\title{
PACTO PELO FORTALECIMENTO DO ENSINO MÉDIO EM RONDÔNIA: (RE) PENSANDO O CURRÍCULO ESCOLAR NOS TERRITÓRIOS DA LINGUAGEM
}

\author{
Mirian de Oliveira BERTOTTTI ${ }^{1}$ \\ Robson Fonseca SIMÕES ${ }^{2}$
}

\section{RESUMO:}

Este texto é um mergulho inicial. Mira colocar em cena o Pacto Nacional pelo Fortalecimento do Ensino Médio em Rondônia, PNEM/RO, um programa de formação continuada do governo federal. As reflexões aqui tratadas são um convite para nos aproximarmos de algumas fontes de pesquisa, procurando ampliar a nossa compreensão sobre esta política de Formação continuada nos territórios da Língua Portuguesa. Mas do que trata esta política para o Ensino Médio? Para esta discussão, valemo-nos dos seguintes autores: Pimenta (2002), Sacristán (2000), Garcia (2013) e Candau (2007) que nos ajudam a refletir sobre possibilidades de abordagens pedagógico-curriculares na área de Linguagens. Sem a pretensão de esgotar o debate, este texto considera importante aprofundar as discussões sobre os componentes curriculares nas veredas da língua, considerando o impacto na melhoria de condições de aprender e desenvolver-se dos sujeitos e dos educadores na etapa conclusiva da Educação Básica.

Palavras - chave: Formação docente. Currículo. Língua portuguesa.

\section{INTRODUÇÃO}

O olho vê, a lembrança revê, a imaginação transvê. É preciso transver o mundo.

Manoel de Barros

A epígrafe deste texto nos instiga a mergulhar na escrita poética de Manoel de Barros, possibilitando-nos pensar que a imaginação, como numa invocação épica, transvê o mundo; nesse sentido, trazer à tona as reflexões sobre as políticas de formação continuada do professor de língua em Rondônia constitui uma possibilidade; em outras palavras, quem sabe, possa ligar os holofotes, numa tentativa de iluminar a discussão acerca das dimensões pedagógicas, políticas, que também fazem andar o carrossel dos desafios pedagógicos dos educadores de língua materna, das estratégias de ensino, das práticas de ensino das linguagens nas veredas da Educação Básica da sociedade contemporânea.

(Re)discutir as questões sobre a fala e a escrita é um caminho que pode contribuir para uma prática reflexiva sobre a língua materna. É nesse sentido que o Ministério da Educação procura convidar os professores de Língua Portuguesa que atuam com os sujeitos do Ensino

\footnotetext{
${ }^{1}$ Mestranda do MEPE/UNIR. Docente de Língua Portuguesa no Instituto Federal de Rondônia/ IFRO. E-mail: mirian.bertotti@ifro.edu.br

2 Docente do Programa de Pós-graduação da Universidade Federal de Rondônia, Mestrado Profissional em Educação Escolar/MEPE. Professor Adjunto da UNIR, Núcleo de Ciências Humanas, Departamento de Ciências da Educação, campus Porto Velho. E-mail: fonsim2000@hotmail.com
} 
Médio a ver com outros olhos as Novas Diretrizes Curriculares Nacionais (2012), sugerindo ações pedagógicas com a língua materna que contemplem a pluralidade, os contextos e a situacionalidade das práticas sociais e educativas da área de Linguagens, abrindo espaço para um processo de aprendizagem significativo e crítico, resultante da participação democrática dos sujeitos envolvidos na escola - sujeitos, docentes, funcionários e comunidade - e das buscas de conhecimento. Essa parceria intitulada Pacto pelo Fortalecimento do Ensino Médio foi lançada em 2013, e busca trazer à baila subsídios para se (re)pensar o currículo escolar e os respectivos componentes curriculares da área de Linguagens.

O fomento para o desenvolvimento de práticas educativas e a busca de um currículo voltado para a formação integral concatenam-se com as críticas que se tecem ao ensino tradicional da Língua Portuguesa nos últimos 50 anos (FARACO 2008), desencadeando inúmeras discussões sobre a prática curricular.

Mais do que apenas levantar questionamentos sobre o papel da linguagem e da língua no processo educacional escolar, o programa Pacto pelo fortalecimento do ensino médio procura instigar no docente a busca por uma reflexão crítica da sua prática educativa.

A vocação deste trabalho, portanto, é procurar trazer à tona algumas considerações sobre esta política educacional implantada em Rondônia, o programa de formação, "Pacto pelo fortalecimento do ensino médio", a sua proposta de um redesenho curricular, e de que forma seus subsídios teóricos enfatizaram as discussões sobre os componentes curriculares que enfocam as representações de mundo, as formas de ação e as manifestações das linguagens, entendendo-as como constitutivas das práticas sociais e, ao mesmo tempo, por elas constituídas.

\section{NAS VEREDAS DO ENSINO MÉDIO: POLÍTICAS PÚBLICAS E EDUCAÇÃO}

Historicamente, inúmeras foram as políticas organizacionais do ensino médio público brasileiro, mas foi com a sansão da lei no 9394/96, a Lei de Diretrizes e Bases da Educação (LDBEN), que se iniciou um ciclo de grande reformulação incorporando o ensino médio a educação básica e instituindo sua finalidade, o que pode ser examinado nos estudos de Garcia (2013):

Nessa etapa de ensino, portanto, são consolidados os conhecimentos necessários para a formação de cidadãos plenos que possam continuar seus estudos e também se inserir no mundo do trabalho, superando a definição de caminhos diferenciados de acordo coma situação socioeconômica de cada sujeito. (GARCIA, 2013, p.49) 
No esforço em buscar melhores índices quantitativos e qualitativos nesta etapa do ensino, várias políticas públicas vêm sendo implantadas, implementadas, e entrelaçam-se, na expectativa de um ensino médio como etapa essencial para uma educação integral, com dimensões omnilaterais ${ }^{3}$. Neste cenário histórico de ações, cabe ressaltar algumas políticas tidas como essenciais para se atingir este objetivo. De 2007, O Plano de Metas Compromisso Todos pela Educação (Decreto n ${ }^{\circ}$ 6.094, de 24 de abril de 2007), o documento trazia à baila uma parceria entre as esferas educacionais federais em um regime de colaboração entre estado, família e comunidade.

Em 2009, o MEC instituia o Programa Ensino Médio Inovador (PROEMI), que objetivava um redesenho do currículo do ensino médio através do apoio e fortalecimento de atividades que visassem à formação integral dos sujeitos, utilizando para isto um currículo que atendesse as necessidades da sociedade contemporânea. Para fortalecer e induzir a uma renovação curricular, o Plano Nacional de Educação (Projeto de Lei no 8.035, de 2010) estipulava uma metas e vários objetivos direcionados, especificamente, a última etapa da educação básica. A meta de número 3 consistia na universalização do atendimento da população escolar de quinze a dezessete anos e a elevação da taxa de matrícula até 2020, no que tange a organização curricular o plano trazia um objetivo que ressaltava a importância da articulação curricular, de concatenar teoria e prática.

Essa perspectiva afirmou-se através das Diretrizes Curriculares Nacionais para o Ensino Médio (Parecer CNE/CEB 05/2011 e Resolução CNE/CEB 02/2012) que elegiam como constituintes de uma formação integral os campos do trabalho, ciência, tecnologia e cultura, o documento norteador destacava a importância de se superar a visão dualista ainda predominante no ensino médio, ora apenas como uma etapa intermediaria para educação superior, ora como inserção no mercado de trabalho;

a última etapa da Educação Básica precisa assumir, dentro de seus objetivos, o compromisso de atender, verdadeiramente, a todos e com qualidade, a diversidade nacional com sua heterogeneidade cultural, de considerar os anseios das diversas juventudes formadas por adolescentes e jovens que acorrem à escola e que são sujeitos concretos com suas múltiplas necessidades (Diretrizes Curriculares Nacionais Gerais da Educação Básica. pag.170. MEC)

\footnotetext{
${ }^{3} \mathrm{O}$ conceito tomado por esta pesquisa encontra-se fundamentado no caderno de formação do programa, que conceitua omnilateralidade da seguinte forma: A omnilateralidade diz respeito à formação integral do ser humano, desenvolvido em todas as suas potencialidades, por meio de um processo educacional que considere a formação científica, tecnológica e humanística, a política e a estética, com vistas à emancipação das pessoas.
} 
Ancorado nestas ações surge o Pacto pelo Fortalecimento do Ensino Médio, instituído pela Portaria no 1.140 , de 22 de novembro de 2013, uma iniciativa federal que se soma a outras políticas educacionais ${ }^{4}$ nacionais desenvolvidas especificamente para esta etapa do ensino. Um programa totalmente voltado à formação do docente, objetivando suscitar discussões sobre a práxis educativa, o currículo escolar,as identidades dos sujeitos envolvidos no ato educativo e a importância da docência. Em um de seus textos, Formação do educador, Rubem Alves (2011), através de sua linguagem simples e poética, já direcionava nosso olhar a figura do educador e de quão importante ela é.

Mas essa escola não se constrói por meio de leis e parafernália tecnológica. De que vale uma cozinha dotada das panelas mais modernas se o cozinheiro não sabe cozinhar? É o cozinheiro que faz a comida boa mesmo em panela velha. O cozinheiro está para a comida boa da mesma forma como o educador está para o prazer de pensar e aprender. Sem o educador o sonho da escola não se realiza. (ALVES, 2011)

Nesse sentido, o convite para as ações pedagógicas foi lançado: é importante que os professores ampliem suas compreensões sobre a totalidade dos componentes curriculares, na forma de disciplinas e outras possibilidades de organização do conhecimento escolar, a partir de algumas dimensões diferenciadas (PNEM, 2014, Etapa II, Caderno IV, Linguagens): a compreensão sobre os sujeitos do Ensino Médio considerando suas experiências e suas necessidades; a escolha de conhecimentos relevantes de modo a produzir conteúdos contextualizados nas diversas situações onde a educação no Ensino Médio é produzida; o planejamento que propicie a explicitação das práticas de docência e que amplie a diversificação das intervenções no sentido da integração nas áreas e entre áreas e a avaliação que permita ao estudante compreender suas aprendizagens e ao docente identificá-las para novos planejamentos.

\section{PACTO DO ENSINO MÉDIO: PARA QUÊ? COMO?}

Entendendo o docente como eixo fundamental no processo educativo, o programa de capacitação e formação é resultante de parcerias entre governo federal, governo estadual, universidades e docentes. Durante o período que foi desenvolvido, de 2013 a 2014, a coordenação geral coube a equipe da Universidade Federal do Paraná, entidade responsável

\footnotetext{
${ }^{4}$ Ao utilizarmos a expressão políticas educacionais estamos nos apropriando da conceituação elaborada por Roseli Batista de Jesus: As políticas educacionais se caracterizam como a ação do Estado com vistas à ordenação de um sistema de educação ou formação e se realizam por meio da prestação de serviços educacionais, tendo as escolas como o meio principal.
} 
tanto pelos encontros interinstitucionais quanto pela elaboração dos cadernos de formação, compartilhando as ações em seminários nacionais, estaduais e cursos de formação docente.

As páginas do seu documento orientador, como num passo de mágica, abriram portas na tentativa de se poder compreender melhor este projeto de formação continuada em Rondônia. Intitulado Documento ${ }^{5}$ orientador das ações de formação continuada de professores e coordenadores pedagógicos do Ensino Médio em 2014, nele há os dados gerais do curso, a organização, o público-alvo, a atividades informativas previstas, o detalhamento do processo formativo na escola, a equipe de formação, os participantes, entre outros dados importantes desse projeto. Vale destacar que o programa não mediu esforços em poder realizar os quatro seminários nacionais, três seminários estaduais, três reuniões técnicas, e que a formação continuada dos docentes do quadro da Secretaria de Estado da Educação de Rondônia ${ }^{6}$ ocorreu em duas etapas, o que também pode ser examinado no documento orientador citado anteriormente.

Para que as etapas da formação fossem realizadas, o programa reuniu uma equipe com funções distintas, perfis e atividades pré-determinadas; juntos, avançavam no debate com o objetivo de aprofundar as discussões sobre a articulação entre conhecimentos das diferentes disciplinas e áreas, a partir da realidade escolar. Ora, a linguagem também fazia parte dessa reflexão; vale destacar que o Pacto Nacional pelo Fortalecimento do Ensino Médio também fomentou a discussão sobre o debate sobre a $\mathrm{Base}^{7}$ Nacional Comum do Currículo que tem sido objeto de estudo dos diversos setores da Educação em todo o território nacional, em articulação com a sociedade, na perspectiva da garantia do direito à aprendizagem e ao desenvolvimento humano dos estudantes da Educação Básica, conforme meta estabelecida no Plano Nacional de Educação.

Os integrantes envolvidos no programa recebiam um auxílio financeiro de incentivo ao estudo e pesquisa com valores que variavam de dois mil a duzentos reais, de acordo com a função exercida dentro da formação.

As linhas do documento orientador do Pacto Nacional pelo Fortalecimento do Ensino Médio (2014) anunciavam a metodologia do curso, com dois movimentos distintos, o primeiro composto por atividades individuais, onde o professor organizava o seu próprio tempo institucional para a leitura dos textos ${ }^{8}$ básicos do curso e apresentava os registros das reflexões realizadas durante suas leituras nas discussões com o grupo na escola. O segundo momento foi

\footnotetext{
${ }^{5}$ Disponível em <http://pactoensinomedio.mec.gov.br/> Acesso em 12/02/2016.

${ }^{6}$ Disponível em <http://www.seduc.ro.gov.br/portal/> Acesso em 12/02/2016.

${ }^{7}$ Disponível em < http:/ / basenacionalcomum.mec.gov.br $>$ Acesso em 12/02/2016.

${ }^{8}$ Cadernos elaborados pela equipe de Educação da Universidade Federal do Paraná.
} 
composto por atividades coletivas. Há de se observar que a formação ocorria na própria escola, em duas etapas

Primeira Etapa: será apresentado um conjunto de temas fundamentados nas DCNEM, para subsidiar a formação continuada do professor. O objetivo é possibilitar a compreensão das diretrizes curriculares nacionais, criando-se um espaço para a reflexão coletiva sobre a prática docente e a importância da participação de todos os atores do processo educativo na reescrita do Projeto Político Pedagógico da escola PPP.(Documento orientador das ações de formação continuada de professores e coordenadores pedagógicos do Ensino Médio em 2014, p.8, 2014. Pág. 08)

Nessa primeira etapa, os pactuandos tinham um compromisso em poder (re) avaliar, pensar o (re)desenho do currículo com base nas Diretrizes Curriculares Nacionais do Ensino Médio (2012); da importância de uma Educação voltada à omnilateralidade,à gestão democrática e ao projeto político pedagógico da escola.

Os materiais didáticos estudados pelos professores abordavam os seguintes eixos temáticos: Ensino médio e formação humana integral; O jovem como sujeito do ensino médio; O currículo do ensino médio, seus sujeitos e o desafio da formação humana integral; Organização e gestão democrática da escola; Áreas de conhecimento e integração curricular e avaliação.

$\mathrm{Na}$ segunda etapa, a formação organizou-se em dois eixos temáticos: organização do trabalho pedagógico no ensino médio e áreas de conhecimento e seus respectivos componentes curriculares, conforme versa as DCNEM (2012).

A figura do orientador de estudos nessa rede de formação fazia a diferença nas formações; responsável pelas atividades metodológicas distintas nas escolas, ele articulava momentos de atividades individuais e coletivas, nas respectivas etapas, o que permitia a oferta de subsídios para se pensar o currículo escolar e os respectivos componentes curriculares da área de Linguagens ${ }^{9}$.

O documento orientador das ações do Pacto Nacional do Ensino Médio também versava sobre o acompanhamento e o monitoramento das atividades desenvolvidas no programa, estas recebidas através de um sistema online administrado pelo Ministério da Educação, o SISMédio. Com informações sobre as atividades desenvolvidas no programa, a

\footnotetext{
${ }^{9}$ Como proposto nas Diretrizes Curriculares Nacionais para o Ensino Médio - DCNEM (BRASIL, 2012), são: Língua Portuguesa, Língua Materna (populações indígenas), Língua Estrangeira (com Língua Espanhola tendo oferta obrigatória, mas facultativa ao aluno), Arte (Artes Visuais, Dança, Música e Teatro) e Educação Física.
} 
frequência dos pactuandos e a vinculação das bolsas de incentivo a pesquisas a estes critérios, o MEC assegurava o andamento do programa.

\section{PACTO DO ENSINO MÉDIO: UM PROGRAMA DE FORMAÇÃO CONTINUADA DOCENTE?}

O Documento Orientador do Pacto Nacional pelo Fortalecimento do Ensino Médio anuncia os dados gerais do curso; nele é possível observarmos dados deste projeto do governo federal que abre portas para se pensar políticas de formação continuada para os professores da rede estadual brasileira:

\footnotetext{
Objetivo geral: Formar em nível de aperfeiçoamento todos os professores e coordenadores pedagógicos que atuam no Ensino Médio com vistas à valorização da formação do professor e dos profissionais da Educação a partir do diálogo entre conhecimentos teóricos e experiências docentes e de gestão pedagógica.

Descrição do Curso: O curso privilegia a articulação entre teoria e a prática no processo de formação docente, fundado no domínio de conhecimentos científicos e didáticos. Considera a escola como lócus de formação continuada e (re)construção coletiva do projeto político-pedagógico em suas articulações com as concepções de juventude e direito à qualidade social da educação. (Documento Orientador das ações pedagógicas para o PNEM, 2014, p. 4, 5)
}

A questão que não quer calar: será que este programa do governo federal pode ser considerado como um curso de formação continuada? Ora, a formação docente continuada pode ser entendida como um aperfeiçoamento da formação já obtida pelo educador, um momento no qual ele pode entrar em contato com as teorias e as discussões educativas, num esforço em se poder renovar as suas práticas pedagógicas e poder (re)construir a sua identidade profissional. Nesta acepção, o Pacto Nacional do Ensino Médio se esforça em poder trazer à baila a oportunidade para uma real e efetiva integração entre os diversos componentes curriculares, considerando o impacto na melhoria de condições de aprender e desenvolver-se dos estudantes e dos professores nessa etapa conclusiva da Educação Básica.

A construção da identidade docente e formação continuada são eixos norteadores do processo educativo e, portanto, despertam inquietudes e debates, Rubem Alves (2011), de uma forma singular, já pontuava: "A questão crucial da educação, portanto, é a formação do educador. 'Como educar os educadores?"

De forma mais efusiva, Pimenta (2002) além de instigar o debate da formação docente, salienta a necessidade de se definir uma identidade profissional que corresponda às demandas do processo formativo exigido pela sociedade contemporânea: "que professor se faz necessário para as necessidades em uma escola que colabore para os processos emancipatórios da 
população?" A autora convida a uma reflexão sobre as novas posturas docentes necessárias atualmente perante o processo ensino-aprendizagem e como a tomada da decisão pedagógica reflete na função da escola, e assim como a sociedade contemporânea é líquida, a identidade profissional docente deve ser volátil.

A identidade profissional docente não é algo imutável, é um processo de construção, reconstrução, de assunção do significado social da profissão. Pimenta (2002) é enfática ao afirmar que:

Uma identidade profissional se constrói, pois, a partir da significação social da profissão; da revisão constante dos significados sociais da profissão; da revisão das tradições. Mas também da reafirmação de práticas consagradas culturalmente e que permanecem significativas. (...) Constrói-se, também, pelo significado que cada professor, enquanto ator e autor, confere à atividade docente no seu cotidiano a partir de seus valores, de seu modo de situar-se no mundo, de sua história de vida, de suas representações, de seus saberes, de suas angústias e anseios, do sentido que tem em sua vida o ser professor. (Pimenta, 2002, p.19)

Ainda sobre a importância da construção da identidade docente, os estudos de Brzezinski (2002) nos ajudam a refletir que a identidade deve ser concebida não apenas em termos de individualidade, mas como uma situação aberta, flexível, isto é, momento do indivíduo em contínuo intercâmbio e em vital interatividade com o coletivo,

é construída no cotidiano, a partir dos pressupostos de exercer sua atividade sobre o alicerce da trilogia dos saberes específicos, dos saberes pedagógicos e das experiências adquiridas dentro e fora da sala de aula, nos desafios enfrentados e superados no exercício da função identidade do educador é um aprendizado continuo, os profissionais devem atualizar,aprimorar e aprofundar os conhecimentos permanentemente para acompanhar as inovações do campo educacional, portanto a formação continuada é um processo essencial nesta construção, identidade profissional e formação continuada estão entrelaçadas. (Brzezinski, 2002, p.131)

É possível entender que na formação continuada do Pacto pelo Fortalecimento do Ensino Médio, o educador seja reconhecido como um sujeito epistêmico, aquele "que elabora e produz conhecimentos com base na compreensão da realidade e nas possibilidades de transformação da sociedade"(Documento orientador do PNEM, 2014, p. 5). Ao considerar a escola como lócus da formação continuada, o programa propõe aos professores voltar os olhos aos sujeitos e situações próprias de cada instituição escolar, salientando a responsabilidade social de todos os envolvidos no processo.

Esta proposta pode ser apoiada na afirmação de António Nóvoa (s/d) quando ressalta a importância de conceber a formação de professores num contexto de responsabilidade 
profissional, sugerindo uma atenção constante à necessidade de mudanças nas rotinas de trabalho, pessoais, coletivas ou organizacionais.

O programa pretendia que os professores fossem levados a troca de experiências, a buscas de soluções para situações-problemas vividas, aos estudos e debates coletivos, características essenciais para uma formação continuada efetiva. Aqui também cabe o destaque para as proposições de Nóvoa (s/d):

(...), a ideia da escola como o lugar da formação dos professores, como o espaço da análise partilhada das práticas, enquanto rotina sistemática de acompanhamento, de supervisão e de reflexão sobre o trabalho docente. $\mathrm{O}$ objectivo é transformar a experiência colectiva em conhecimento profissional e ligar a formação de professores ao desenvolvimento de projectos educativos nas escolas. (...), a ideia da docência como colectivo, não só no plano do conhecimento mas também no plano da ética. (...) Por isso, é tão importante assumir uma ética profissional que se constrói no diálogo com os outros colegas. (NÒVOA, s/d, p.7)

Com a proposta elaborada pela atual DCNEM (2012), o ensino médio está fundamentado nos seguintes pressupostos: "trabalho, ciência, tecnologia e cultura: dimensões da formação humana; trabalho como princípio educativo; pesquisa como princípio pedagógico, direitos humanos como princípio norteador e sustentabilidade socioambiental como meta universal ${ }^{10}$ '. Para atender a essas necessidades e materializar esses pressupostos é que a formação continuada justifica-se:

as políticas atuais de formação, deverão transcender o caráter emergencial e descontínuo, aprofundando a consistência teórica e qualificando a formação do professor para o desenvolvimento de uma prática que atenda as demandas dos estudantes e da sociedade a partir do desenvolvimento de um currículo orientado a partir das DCNEM.(...)Também é fundamental garantir a formação continuada desses profissionais. No caso do ensino médio, a formação continuada é estratégica e indispensável, pois muitos dos professores dessa etapa educacional, em geral, não tiveram formação na perspectiva tratada nas atuais DCNEM. Isto ocorre por várias razões, uma delas é que se está diante de uma nova concepção de ensino médio no quadro educacional brasileiro. (Documento de apresentação do Pacto, p. 14 e 15).

Portanto, a ampliação de saberes envolve experienciar e contrastar práticas diversas, gerando debates, pesquisas, e a reflexão sobre o próprio processo de inserção nessas práticas, de modo que os estudantes desenvolvam autonomia para sua atuação na escola ou além dos muros escolares.

\footnotetext{
${ }^{10} \mathrm{O}$ que se confere no documento de apresentação do PNEM.
} 


\section{DIREITOS À APRENDIZAGEM: PACTO DO ENSINO MÉDIO, CURRÍCULO E EDUCAÇÃO}

Há variadas concepções associadas à palavra currículo; elas advêm das formas pelas quais a Educação é concebida, e qual o seu papel, a sua importância na sociedade; o que nos instiga a refletir sobre diferentes posicionamentos, compromissos e pontos de vista teóricos surgidos de fatores socioeconômicos, políticos e culturais (MOREIRA; CANDAU, 2007). A conceituação de currículo é tão complexa que sobre este tema Sacristán (2000, p.19) sugere: "não é estranho encontrar-se com perspectivas diversas que selecionam pontos de vista, aspectos parciais, enfoques alternativos com diferente amplitude".

Apesar de variadas acepções e perspectivas sobre o assunto, o próprio Sacristán (2000, p. 15) assim o refletiu: "o currículo é uma práxis antes que um objeto estático emanado de um modelo coerente de pensar a educação ou as aprendizagens necessárias”.

Entender a práxis como "um movimento operacionalizado simultaneamente pela ação e reflexão" (GHEDIN, 2002 p.133) resulta o entendimento de que currículo não são apenas conteúdos programáticos, processos avaliativos, planos pedagógicos, Moreira e Candau (2007) assim o definem:

estamos entendendo currículo como as experiências escolares que se desdobram em torno do conhecimento, em meio a relações sociais, e que contribuem para a construção das identidades de nossos/as estudantes. Currículo associa-se, assim, ao conjunto de esforços pedagógicos desenvolvidos com intenções educativas.(Moreira e Candau, 2007 p.18)

O currículo pode ser compreendido como a concretização da função social da instituição escolar; aos educadores cabe a análise e as constantes discussões, de forma crítica e criativa, para torná-lo mais eficiente e atrativo. "O papel do educador no processo curricular é, assim, fundamental. Ele é um dos grandes artífices, queira ou não, da construção dos currículos que se materializam nas escolas e nas salas de aula" (MOREIRA; CANDAU, 2007p. 19)

No debate sobre o (re)desenho curricular do ensino médio,o Pacto cumpria o seu papel, procurando instigar nos docentes e coordenadores as discussões sobre o currículo e a sua forma de organização no módulo intitulado: O currículo do ensino médio, seus sujeitos e o desafio da formação humana integral, abrindo portas para os subsídios teóricos que sustentavam as reflexões e permitiam a concretização dos pressupostos fornecidos pelo programa.

Com o intuito de aproximar os educadores das DCNEM (2012), o caderno de formação apresentava a necessidade de o currículo atender as expectativas de uma Educação integral, 
associada as quatro dimensões: trabalho, cultura, ciência e tecnologia ${ }^{11}$, já que é possível entender que a proposta curricular fragmentada não atende mais as expectativas dos sujeitos do Ensino Médio.

(...) é possível verificar que a organização curricular do ensino médio que se instituiu ao longo do tempo se caracterizou pela fragmentação do conhecimento em disciplinas estanques e hierarquizadas, de modo a valorizar algumas áreas do conhecimento em detrimento de outras. Essa perspectiva curricular, no entanto, evidenciou seus limites, seja no que é praticado nas escolas, seja nos processos formativos dos novos professores. Entre as limitações, podemos sinalizar sua estruturação com base em um conjunto de saberes os quais nada ou pouco explicam, por serem dissociados da realidade vivida, experimentada.(Caderno III: O currículo do ensino médio, seus sujeitos e o desafio da formação humana integral, p. 07)

Ao mediar discussões sobre o currículo, o programa do governo federal procurou despertar a sensibilidade para os envolvidos na prática educativa; os sujeitos da ação, suas respectivas identidades e necessidades e voltar os saberes e experiências docentes a uma formação plena, reconhecendo os educandos do ensino médio como sujeitos de direito. Esses debates permeavam constantemente o caderno de formação e serviam como um chamamento ao docente

(...) a necessidade de pensarmos as proposições curriculares para o ensino médio suas intenções e práticas, seus materiais, seus tempos e espaços, tendo como referencial permanente os jovens alunos que o frequentam, suas expectativas, seus desejos, suas necessidades. Isso implica grande desafio se considerarmos que muitas das decisões tomadas para o ensino médio em termos de currículo desconsideraram essas razões e privilegiaram objetivos ora vinculados aos processos seletivos e excludentes, ora determinados por questões econômicas que entendiam seu papel como formador para o mercado de trabalho. (Caderno III: O currículo do ensino médio, seus sujeitos e o desafio da formação humana integral, p. 23)

\footnotetext{
${ }^{11}$ Segundo o caderno de formação as dimensões são assim conceituadas: trabalho: o compreendermos como uma mediação central no processo de produção da existência e objetivação da vida humana; cultura:é entendida como as diferentes formas de criação da sociedade, incluindo as práticas de produção da existência humana, seus valores, suas normas de conduta, suas obras; ciência:é a parte do conhecimento sistematizado e deliberadamente expresso na forma de conceitos representativos das relações determinadas e apreendidas da realidade considerada; tecnologia: resulta da transformação da ciência em força produtiva; não é simplesmente aplicação técnica do conhecimento científico, pois a transformação deste em tecnologia envolve decisões que, por sua vez, dependem dos interesses em jogo na sociedade e dos caminhos seguidos pelo desenvolvimento científico e tecnológico.
} 
O currículo não é uma organização neutra, técnica, é uma construção política da instituição escolar com reflexos diretos em todos os envolvidos, norteador das ações pedagógicas, do trabalho docente, é o currículo "o coração da escola", como denominaram Moreira e Candau (2007).

\section{ENSINO DE LÍNGUA E LINGUAGEM: DIÁLOGOS COM A VIDA}

O debate sobre a organização curricular levou os pactuandos a permearem o arranjo curricular estipulado pelas DCNEM (2012); estas ações pedagógicas se miram colocar em cena os vários componentes curriculares interligados e propõe um ensino contextualizado, transdisciplinar e pluralizado. Como proposta de formação continuada, o programa ofereceu aos cursistas, o material ${ }^{12}$ de apoio, voltado especificamente a área de conhecimento da língua intitulado Linguagens.

Conforme descrito pela DCNEM (2012), a área de Linguagens compreende os seguintes componentes obrigatórios: Língua Portuguesa; língua materna para populações indígenas; língua estrangeira moderna; Arte e Educação Física. A busca por novas abordagens e reflexões que contemplem a pluralidade, contextos significativos e criticidade ratificam a importância desta área e de seus campos.

(...) essa área ganha um núcleo definidor à medida que todos os seus componentes se voltam para os conhecimentos e saberes relativos às interações e às expressões do sujeito em práticas socioculturais. Ou seja, como área, todos os componentes curriculares arrolados acima, de algum modo, enfocam as representações de mundo, as formas de ação e as manifestações de linguagens, entendendo-as como constitutivas das práticas sociais e, ao mesmo tempo, por elas constituídas.(Formação de professores do ensino médio, Etapa II - Caderno IV, 2014, p. 7)

O elo entre os componentes curriculares é o uso da linguagem como parte do processo de ensino e de aprendizagem, como elemento fundamental de atuação do sujeito em práticas sociais diversas, Koch (2003, p. 7), de forma simplista, delimita a linguagem "como forma de ação ou interação", o ser humano é percebido como produto das relações e ações sociais, que vai construindo suas capacidades discursivas ao mesmo tempo em que vai se constituindo como sujeito em modos e tempos diversos através do convívio com outras vozes, outros entendimentos e pontos de vista diferenciados.

\footnotetext{
${ }^{12}$ Caderno da etapa II elaborado pela equipe de Educação da Universidade Federal do Paraná.
} 
Ao compreender a amplitude dessa concepção, exige-se o desenvolvimento de atividades educativas que façam sentidos aos sujeitos, "eles precisam ser contemplados em uma interação autêntica, onde haja espaço para as opiniões, os debates, as decisões."(PNEM, Etapa II - Caderno IV, 2014, p. 16).Apoiando-se nesse ideário, a formação instiga os educadores a transporem a visão mimética do currículo, e convida os docentes de língua portuguesa a repensarem suas práticas educativas, muitas delas baseadas em um ensino imitativo e reprodutivo.

Os estudos de Antunes (2009) já destacavam a importância de se direcionar o ensino da língua a atividades centradas na pratica discursiva baseadas em funções comunicativas e contextos culturais diversos, e sobre isso alertou:

(...) já contamos com elementos a partir dos quais podemos traçar um caminho de ensino de língua que se distancie da mera exploração da metalinguagem, com suas nomenclaturas e classificações infindáveis e que seja centrado nas funções sociais de interação verbal. (ANTUNES, 2009 p. 233)

Faraco (2008) destaca a necessidade de que os docentes realizem com os educandos uma ação reflexiva sobre a língua, "integrando as atividades verbais e o pensar sobre elas", destacando ainda "a imensa variedade de formas expressivas alternativas à disposição do falante".E ainda ressalta: "Refletir sobre a estrutura da língua e sobre seu funcionamento social é atividade auxiliar indispensável para o domínio fluente da fala e da escrita." (FARACO, 2008, p.157)

Aqui, cabe destaque, novamente, ao fazer pedagógico dos professores de língua, que deve ser tomado como um posicionamento ético e social frente às inúmeras formas de aprendizagem e desenvolvimento dos educandos.

\section{RUMO ÀS AÇÕES PEDAGÓGICAS DIFERENCIADAS: CONSIDERAÇÕES FINAIS}

Um olhar historiográfico para o currículo do Ensino Médio público brasileiro, desde a lei 9394/96, ajuda-nos a tecer uma história de reformulações: a sua inclusão na Educação Básica, propiciando políticas de acesso, permanência e financiamento; a busca pelo desenvolvimento de competências e habilidades na aprendizagem dos sujeitos; o ressurgimento do ensino técnico concomitante com o Ensino Médio, o que traz à tona questões sobre o ensino propedêutico. É possível pensar que elas trazem uma rubrica das políticas educacionais. 
Com o desenvolvimento acelerado das inúmeras tecnologias e, consequentemente, da nossa sociedade é natural que outras necessidades e habilidades surjam e evoquem dos sujeitos competências para entendê-las e manipulá-las; esta necessidade por processar linguagens é um assunto da Educação; tem reflexos na escola, sobretudo nos sujeitos do Ensino Médio, que buscam na instituição escolar saberes que contemplem conhecimentos necessários às interações e às expressões nas práticas sociais. Por estes motivos, não é difícil entendermos que as ações educativas fragmentadas não atendem as expectativas sociais contemporâneas; o que pode novamente nos remeter ao poeta Manoel de Barros; é preciso transver o mundo.

As novas políticas educacionais, diretrizes curriculares, planos de educação, programas governamentais ampliam o debate democrático nos territórios da Educação, fazendo andar a nova organização curricular para alcançar o ideário da educação integral. Nesse contexto, a formação continuada docente é uma bandeira de luta e de força dos professores e dos sujeitos.

O programa citado nesta pesquisa, visava o estímulo ao debate sobre a organização curricular desenhada pelas NDCNEM (2012), a responsabilidade dos educadores nas práticas pedagógicas da escola e a tomada de uma práxis reflexiva. Apesar de serem reflexões iniciais que se debruçam no documento oficial do Pacto Nacional do ensino Médio, é louvável a ação formadora tomar como lócus de formação a escola, para que os docentes percebam e sintamse como parte integrante e modificadora do ambiente escolar.

Vale ressaltar ainda o incentivo financeiro à pesquisa e ao estudo, que motivaram os docentes e, de certa forma, garantiram a permanência no programa. No que tange ao ensino de língua, as atividades do caderno de formação sobre Linguagens procuraram ampliar as possibilidades de um ensino contextualizado, priorizando a interação verbal e as inúmeras situações comunicativas, despertaram a sensibilidade para o desenvolvimento de uma organização curricular que privilegie o trabalho transdisciplinar.

Ao instigar discussões necessárias aos docentes sobre a prática e a organização da escola, o Pacto Nacional para o Fortalecimento do Ensino Médio em Rondônia vislumbrou alcançar horizontes nunca antes navegados, permitindo que os educadores (re)pensem as suas práticas educativas,vistas como atitudes éticas, políticas e sociais e por isso, emancipadoras. 
PACT FOR STRENGTHENING OF HIGH SCHOOL IN RONDONIA: (RE) THINKING THE SCHOOL CURRICULUM IN LANGUAGES TERRITORIES

\begin{abstract}
This text is an initial dip. It aims to put to stage the National Pact for Strengthening of High School in Rondônia, PNEM/RO, a program of continuing education of the federal government. The reflections here treated are an invitation to approach us some research sources, seeking to expand our comprehension on this continuing education policy in the territories of Portuguese Language. But what does this policy for the High School look after? For this discussion, we make use of the follow authors: Pimenta (2002), Sacristán (2000), Garcia (2013) and Candau (2007) who help us to reflect about possibilities of pedagogical-curricular approaches in the Language areas. Without pretension to exhaust the debate, this text considers that is important to deepen the discussions on the curricular components in the language paths, considering the impact in the improvement of conditions to learn and develop in subjects and educators at the final stage of Basic Education.
\end{abstract}

Keywords: Teacher Training. Curriculum. Portuguese Language. 


\section{REFERÊNCIAS}

ALVES, Rubem. A formação do educador. Disponível em: http://revistaeducacao.com.br/textos/124/artigo234219-1.asp.Acesso: 21/12/2015

ANTUNES, Irandé. Língua, texto e ensino: outra escola possível. São Paulo. Parábola Editorial, 2009.

BRASIL. Lei de Diretrizes de Bases da Educação Nacional. (Lei no 9.394 promulgada em 20/12/1996): Editora do Brasil. 1996

BRASIL. Plano de Metas Compromisso Todos pela Educação (Decreto n ${ }^{\circ}$ 6.094, de 24 de abril de 2007), Disponível em: http://www.planalto.gov.br/ccivil 03/ ato20072010/2007/decreto/d6094.html .Acesso em: 22/12/2015

Plano Nacional de Educação (Projeto de Lei no 8.035, de 2010). Disponível em: http://www.camara.gov.br/sileg/integras/831421.pdf . Acesso em: 22/12/2015.

.Diretrizes e as Diretrizes Curriculares Nacionais do Ensino Médio (Resolução CNE/CEB $\mathrm{n}^{\circ}$ 2, de 30 de janeiro de 2012). Disponível em: http://portal.mec.gov.br/index.php?option $=$ com docman\&view $=$ download\&alias $=15548-\mathrm{d}$ c-n-educacao-basica-nova-pdf\&Itemid=30192. Acesso: 04/01/16.

Documento de apresentação do pacto. Disponível em: http://pactoensinomedio.mec.gov.br/images/pdf/pacto fort ensino medio.pdf . Acesso: $15 / 01 / 16$

BRASIL. MEC.Secretaria de Educação Básica. Formação de professores do ensino médio, etapa I - caderno III: o currículo do ensino médio, seu sujeito e o desafio da formação humana integral. Curitiba: UFPR/Setor de Educação, 2013.

Formação de professores do ensino médio, Etapa II - Caderno IV: Linguagens. Curitiba: UFPR/Setor de Educação, 2014.

BRZEZINSKI, Íria. Profissão professor, identidade e profissionalização docente. Brasília. Plano Editora. 2002.

FARACO, Carlos Alberto. Norma culta brasileira: desatando alguns nós. São Paulo: Parábola editorial, 2008.

FREIRE, Paulo. Pedagogia da Autonomia: saberes necessários à prática educativa. São Paulo: Paz e Terra, 1996.

GARCIA, Regina de Oliveira. Reestruturação do Ensino Médio: pressupostos teóricos e desafios da prática. São Paulo: Fundação Santillana, 2013.

GHEDIN, Evandro. Professor reflexivo: da alienação técnica à autonomia da crítica in Professor reflexivo no Brasil: gênese e critica de um conceito. São Paulo: Cortez. 2002. Selma garrido pimenta. Evandro Ghedin. (orgs).

KOCH, Ingedore Grunfeld Villaça. A inter-ação pela linguagem. 8. Ed. São Paulo: Contexto, 2003. 
MINISTÉRIO DA EDUCAÇÃO. Documento orientador das ações de formação continuada de professores e coordenadores pedagógicos do Ensino Médio em 2014. 2014.

MOREIRA, Antônio Flavio Barbosa; CANDAU, Vera Maria. Indagações sobre o currículo: currículo, conhecimento e cultura. Brasília: Ministério da educação, Secretaria de Educação Básica, 2007.

NÓVOA, António. Para uma formação de professores construída dentro da profissão. Disponível em: http://www.revistaeducacion.educacion.es/re350/re350 09por.pdf. Acesso: 13/01/2016.

PIMENTA, Selma Garrido. Formação de professores: identidade e saberes da docência. P.1534. In: PIMENTA, Selma Garrido (org.). Saberes pedagógicos e atividade docente. $3^{\text {a }}$ ed. São Paulo: Cortez, 2002.

SACRISTÁN, J. Gimeno. O currículo: uma reflexão sobre a prática. $3^{a}$ Ed. Porto Alegre: Armed, 2000. 